\title{
Polymorphism of Gly39Glu (c.116G >A) hMSH6 is associated with sporadic colorectal cancer development in the Polish population: Preliminary results
}

\author{
Piotr Zelga ${ }^{1, A-D}$, Karolina Przybyłowska-Sygut ${ }^{2, A, C, E}$, Marta Zelga ${ }^{1, B, C}$, Adam Dziki ${ }^{1, A, ~ E, ~ F, ~ I r e n e u s z ~ M a j s t e r e k ~}{ }^{2, A, E, F}$ \\ ${ }^{1}$ General and Colorectal Surgery Department, Medical University of Lodz, Poland \\ ${ }^{2}$ Department of Biochemistry, Medical University of Lodz, Poland \\ A - research concept and design; $\mathrm{B}$ - collection and/or assembly of data; $\mathrm{C}$ - data analysis and interpretation; \\ $D$ - writing the article; $E$ - critical revision of the article; $F$ - final approval of the article
}

Address for correspondence

\section{Piotr Zelga}

E-mail: piotr_zelga@op.pl

\section{Funding sources}

This study was supported by the Medical

University of Lodz Grant 502-03/5-120-02/

502-54-089.

Conflict of interest

None declared

Received on March 20, 2016

Reviewed on July 10, 2016

Accepted on August 29, 2016

\begin{abstract}
Background. Colorectal cancer (CRC) remains a major source of cancer-related mortality, accounting for 10\% of all cancer-related deaths. DNA mismatch repair mechanism (MMR) responsible for correcting errors generated during DNA replication and its deficiency is associated with both hereditary and sporadic CRC. Single-nucleotide polymorphisms (SNPS) are the most common forms of genetic variation, and it has been shown that the SNPs in MMR genes may modify CRC risk.

Objectives. The aim of the study was to determine the relationship between gene polymorphism Glu39Gly (c.116G $>A$ ) of the hMSH6 gene and the modulation of the risk of sporadic colorectal cancer in the Polish population.
\end{abstract}

Material and methods. A total of 128 patients with resectable colorectal carcinoma as well as 189 sex-, age-, and ethnicity-matched control subjects without cancer history were enrolled in this study. Patients with a family history of CRC or inflammatory bowel diseases were excluded from this study. The DNA was isolated from peripheral blood lymphocytes of enrolled patients, and gene polymorphisms were analyzed by restriction fragment length polymorphism-polymerase chain reaction (RFLP-PCR).

Results. We observed that the genotype G/A variant of Glu39Gly (c.116G>A) genotype is associated with an increased risk of colorectal cancer (OR 1.65; $95 \%$ Cl: 1.01-2.69; $p=0.44)$. The presence of $A$ allele was also significantly higher in patients with CRC (OR 1.57; 95\% Cl: 1.04-2.38; $p=0.032)$. When comparing the prevalence of genotypes with clinical staging, genotype $G / A$ and $A$ allele were significantly less frequent in stage III-IV than in I (OR 0.3409; $95 \%$ Cl: $0.124-0.939 ; p=0.0375$, and OR 0.4462; $95 \%$ Cl: $0.201-0.991$; $p=0.044$, respectively).

Conclusions. These findings suggest that hMSH6 Glu39Gly polymorphism is associated with the risk of developing colorectal cancer in the Polish population, probably due to a defective mismatch repair system. The presence of $\mathrm{G} / \mathrm{A}$ genotype and $\mathrm{A}$ allele is, however, associated with less advanced disease.

Key words: colorectal cancer, SNP, hMSH6, DNA MMR

DOI

10.17219/acem/64877

\section{Copyright}

Copyright by Author(s)

This is an article distributed under the terms of the

Creative Commons Attribution Non-Commercial License

(http://creativecommons.org/licenses/by-nc-nd/4.0/) 


\section{Introduction}

Colorectal cancer (CRC) is the most common gastrointestinal malignancy. Only in the USA, around 13,449 new cases are expected to be diagnosed with colorectal malignancy with the estimated mortality of about 49,190 in $2016 .{ }^{1}$ In the past decade, there has been a significant general decrease in the incidence of CRC associated mortality observed in Western countries. ${ }^{2}$ On the other hand, incidence rates are increasing among adults younger than 50 years of age and in certain countries with historically low prevalence of CRC, e.g., Eastern Europe. ${ }^{1}$ Although often viewed as a single disease, CRC more accurately represents a constellation of heterogeneous subtypes that result from different combinations of genetic events and epigenetic alterations. ${ }^{3}$ Although the majority of CRCs are the results of chromosomal instability, approx. 15\% of cancers develop via an alternative pathway characterized by defective function of the DNA mismatch repair (MMR) system. ${ }^{4}$ The MMR system recognizes and corrects mismatched bases and small insertion-deletion loops generated during DNA replication. Highly conserved series of proteins, including MSH2, MSH6, MSH3, MLH1, PMS2, PCNA, and EXO1 are involved in the MMR system, which operates functionally, forming 2 heterodimers: hMSH2-hMSH6 and hMSH2-hMSH3. The recognition of mismatches and insertion-deletion loops are carried by these 2 heterodimers, respectively. This process is coordinated by another heterodimer formed out of MLH1 and PMS2. Inefficient function of the MMR system leads to the accumulation of mutations, resulting from the inability to repair single nucleotide DNA mismatches, particularly in highly repeated sequences known as microsatellite instability (MSI). Germline mutations in $M M R$ genes or hypermethylation of the MLH1 promoter lead to a deficient MMR system (MMR-D) and a high degree of MSI in genome, resulting in the development of a variety of human cancers, e.g., endometrial or gastric cancer. MMR-D accounts for $15 \%$ of all CRCs, with $3 \%$ being associated with hereditary non-polyposis colorectal carcinoma (HNPCC), and the remaining $12 \%$ arise sporadically. ${ }^{5}$ Although the prevalence could vary between populations, it is clear that the MSI phenotype represents a clinically meaningful proportion of CRCs. On the other hand, lots of CRCs are sporadic and have a proficient MMR system with low-frequency MSI. It is, however, widely hypothesized that the heritable nature of CRC might be associated with the co-inheritance of multiple low-risk variants that may also further interact with environmental factors. ${ }^{6,7}$ This hypothesis was supported by the identification of single-nucleotide polymorphisms (SNPs) localized in different genomic regions that influence the risk of CRC. ${ }^{8}$ SNPs of $M M R$ genes may alter the gene and protein expression pattern, thus modifying its efficacy and therefore the risk of developing CRC. The risk of CRC associated with each of the vari- ants is individually low, but the combined effect of these variants could significantly contribute to disease development, especially given the high prevalence of these variants in the general population. ${ }^{9}$ MSH6 Gly39Glu (116G>A) polymorphism (rs1042821) first described by Nicolaides, et al. has been investigated for the role in its development of both HNPCC and sporadic CRCs. ${ }^{10}$ The inactivating mutations of MSH6 in yeast and human tumor cell lines are associated with an impaired ability to repair singlebase mispairs and small insertion-deletion loops but not large insertion-deletion loops. ${ }^{11}$ This indicates that hMSH6 mutations are prone to be associated with a MSI-L phenotype than a MSI-H phenotype, which is more typical to sporadic CRC. MSI-L colorectal tumors have been proposed as possible candidates for hMSH6 mutations by Wu. ${ }^{12}$ Berndt and Campbell reported an association between MSH6 Gly39Glu (116G>A) polymorphism and the development of rectal and colon cancer. ${ }^{13,14}$ However, the results of further studies were conflicting. ${ }^{11,15}$ These reports prompted us to investigate a common polymorphism in the MSH6 gene of MMR system and their role in the susceptibility to sporadic colorectal cancer in the population of our region.

\section{Material and methods}

Test DNA was isolated from peripheral blood samples collected from 128 unrelated patients with confirmed CRC. Only patients with a resectable disease were enrolled into the study. Blood samples for the analysis were taken on the day of admission in both groups of patients. A detailed characteristic of the patients with the CRC is shown in Table 1. The control group consisted of 189 patients hospitalized in the same surgical ward without any medical history of cancer, inflammatory diseases and diabetes. The reason for hospitalization was mostly benign proctological disease or hernia. The analyzed and control groups members were age- and sex-matched.

\section{Detection of $h M S H 6$ gene mutation}

The DNA for genotyping was isolated from the blood samples of CRC patients using a commercial kit QIAamp DNA Blood Mini Kit for isolating high-molecular-weight DNA (Qiagen). Detection of Gly39Glu (c.116G>A ) polymorphisms of the $h M S H 6$ gene was carried out by RFLPPCR analysis. Primers used for amplifications of the analyzed region are shown in Table 2. PCR products were generated using, in each reaction, a total volume of $20 \mu \mathrm{L}$ containing $10 \mathrm{pM}$ of each primer, $1 \mathrm{U}$ Taq DNA polymerase (Qiagen), $0.2 \mathrm{~mm}$ of each dNTP, $1.5 \mathrm{mM} \mathrm{MgCl}_{2}$, and $50 \mathrm{mM} \mathrm{KCl}, 20 \mathrm{mM}$ Tris- $\mathrm{HCl}(\mathrm{pH}=8.4)$, and $50 \mathrm{ng}$ of genomic DNA. PCR amplification was performed in MultiGene TC9600-G termocycler (Labnet International, Inc., Edison, USA) under the following conditions: 
Table 1. Primers used for RFLP-PCR

\begin{tabular}{|c|c|c|}
\hline Gene & Direction & Sequence \\
\hline \multirow{2}{*}{ MSH6 Gly39Glu (116G>A) polymorphism (rs1042821) } & forward & 5'-GCG CTG AGT GAT GCC AAC AAG-3' \\
\hline & reverse & 5'-CAG CAG GCG CTA CCG ATC TC-3' \\
\hline
\end{tabular}

initial denaturation at 1 cycle at $95^{\circ} \mathrm{C}$ for $5 \mathrm{~min}$ and amplification of 35 cycles $\left(30 \mathrm{~s}\right.$ at $95^{\circ} \mathrm{C}, 30 \mathrm{~s}$ at $55^{\circ} \mathrm{C}$, and $30 \mathrm{~s}$ at $72^{\circ} \mathrm{C}$ ), followed by a final cycle of $7 \mathrm{~min}$ at $72^{\circ} \mathrm{C} ; 8 \mu \mathrm{l}$ of PCR products was diluted in $2 \mu \mathrm{l}$ of denaturation buffer $(95 \%$ formamide, $0.05 \%$ bromophenol blue, and $0.05 \%$ xylene cyanol) and was separated on a $1.5 \%$ polyacrylamid gel at $10 \mathrm{~V} / \mathrm{cm}$ for $1 \mathrm{~h}$ at room temperature. The final products were visualized by ethidium bromide staining.

\section{Statistical analysis}

The statistical analysis was conducted using STATISTICA software v. 13 PL (StatSoft, Inc.). The resulting number of each genotype was compared with the expected value based on the Hardy-Weinberg equilibrium. The significance of differences between the frequencies of alleles and genotypes between the groups was assessed using the $X^{2}$ test and the Fisher exact test. Odds ratio (OR) with corresponding confidence interval 95\% (CI 95\%) were calculated during multivariate regression analysis.

\section{Results}

Distributions of genotypes and alleles in the CRC and control group are presented in Table 3. G allele has been used in our study as a reference in calculations. According to the Hardy-Weinberg $X^{2}$ analysis, the distribution of genotypes and alleles in CRC group and the control group was not consistent with $\mathrm{H}-\mathrm{W}$ equilibrium $\left(\mathrm{X}^{2}=0.07\right.$, $\mathrm{p}=0.786$ and $\mathrm{X}^{2}=0.34, \mathrm{p}=0.558$, respectively). No significant difference in alleles or genotypes distribution was observed between age and sex groups $(<60,>60$, females, males). Risk of CRC was approximately 2 -fold higher for the G/A genotype (OR 1.57; 95\% CI: 1.04-2.38; p = 0.032)
Table 2. Clinical and pathological characteristics of the analyzed group of patients with colorectal cancer

\begin{tabular}{|l|c|}
\multicolumn{1}{|c|}{ Characteristic } & $\begin{array}{c}\text { Patients } \\
\mathrm{n}(\%)\end{array}$ \\
\hline Gender & \\
\hline male & $54(42)$ \\
\hline female & $74(58)$ \\
\hline Age & \\
\hline$<60$ years & $40(31)$ \\
\hline$>60$ years & $88(69)$ \\
\hline Localization & \\
\hline colon & $65(51)$ \\
\hline rectum & $63(49)$ \\
\hline Histology & \\
\hline adenocarcinoma tubulare & $61(47)$ \\
\hline adenocarcinoma muccosinum & $55(44)$ \\
\hline adenocarcinoma planoepitheliale & $12(9)$ \\
\hline Grading & \\
\hline 1 & $21(17)$ \\
\hline 2 & $100(78)$ \\
\hline 3 & $7(5)$ \\
\hline TNM Classification & $62(48)$ \\
\hline I and II & $66(52)$ \\
\hline III and IV & \\
\hline
\end{tabular}

and A allele (OR 1.65; 95\% CI: 1.01-2.69; p = 0.44). When comparing the prevalence of genotypes with clinical staging, genotype G/A and A allele were significantly less frequent in stage III-IV than in I (OR 0.3409; 95\% CI: 0.1240.939; $\mathrm{p}=0.0375$, and OR 0.4462; 95\% CI: 0.201-0.991; $\mathrm{p}=0.044$, respectively) (Table 4 ).

Table 3. Genotypes and alleles distribution of Gly39Glu (c. 116G>A) polymorphism of hMSH6 gene in patients with colorectal cancer and in control group

\begin{tabular}{|c|c|c|c|c|}
\hline $\begin{array}{c}\text { Genotype } \\
\text { Allele }\end{array}$ & $\begin{array}{c}\text { CRC patients } \\
(\mathrm{n}=128) \\
\text { number (frequency) }\end{array}$ & $\begin{array}{c}\text { Control group } \\
(\mathrm{n}=189) \\
\text { number (frequency) }\end{array}$ & OR (Cl 95\%) & $p$-value \\
\hline \multicolumn{5}{|c|}{ additive model } \\
\hline $\mathrm{G} / \mathrm{G}$ & $80(0.63)$ & $137(0.72)$ & \multicolumn{2}{|c|}{1 Ref. } \\
\hline$G / A$ & $44(0.34)$ & $49(0.26)$ & $1.65(1.01-2.69)$ & 0.044 \\
\hline$A / A$ & $4(0.03)$ & $3(0.02)$ & $2.34(0.51-10.73)$ & 0.230 \\
\hline G & $204(0.8)$ & $323(0.85)$ & \multicolumn{2}{|c|}{ Ref. } \\
\hline A & $52(0.21)$ & $55(0.15)$ & $1.57(1.04-2.38)$ & 0.032 \\
\hline
\end{tabular}


Table 4. Genotypes and alleles distribution of Gly39Glu (c. 116G>A) polymorphism of hMSH6 gene in patients with colorectal cancer according to staging by American Joint Committee on Cancer

\begin{tabular}{|c|c|c|c|c|c|c|c|c|c|}
\hline \multirow[b]{2}{*}{$\begin{array}{c}\text { Genotypes/ } \\
\text { alleles }\end{array}$} & \multicolumn{3}{|c|}{ Patients $n=128$} & \multicolumn{2}{|l|}{$\| I^{\circ}$ vs $I^{\circ}$} & \multicolumn{2}{|l|}{$\mid I I^{\circ}$ vs $^{\circ}$} & \multicolumn{2}{|l|}{$\| I^{\circ}$ vs $I^{\circ}$} \\
\hline & $\begin{array}{c}\mathrm{I}^{\circ} \\
(\mathrm{T} 1-2 \mathrm{~N} 0)\end{array}$ & $\begin{array}{c}I^{\circ} \\
(\mathrm{T} 3-4 \mathrm{NO})\end{array}$ & $\begin{array}{c}\mathrm{II}^{\circ} \mathrm{i}_{\mathrm{IV}}^{\circ} \\
(\mathrm{T} 1-4 \\
\mathrm{N} 1-2 \mathrm{M0} \\
\mathrm{i} \mathrm{M} 1)\end{array}$ & OR $(95 \% \mathrm{Cl})$ & $p$-value & OR $(95 \% \mathrm{Cl})$ & p-value & OR $(95 \% \mathrm{Cl})$ & p-value \\
\hline $\mathrm{G} / \mathrm{G}$ & 9 & 25 & 46 & \multicolumn{2}{|l|}{1 (ref) } & \multicolumn{2}{|l|}{1 (ref) } & \multicolumn{2}{|l|}{1 (ref) } \\
\hline $\mathrm{G} / \mathrm{A}$ & 11 & 15 & 18 & $0.5245(0.1805-1.5236)$ & 0.185 & $0.3409(0.1238-0.9391)$ & 0.0375 & $1.472(0.6495-3.336)$ & 0.403 \\
\hline$A / A$ & 1 & 1 & 2 & $0.5(0.0297-8.4166)$ & 1 & $0.625(0.0538-7.2605)$ & 1 & 1.25 (0.1097-14.2383) & 1 \\
\hline G & 29 & 65 & 110 & \multicolumn{2}{|l|}{1 (ref) } & \multicolumn{2}{|l|}{1 (ref) } & \multicolumn{2}{|l|}{1 (ref) } \\
\hline$A$ & 13 & 17 & 22 & $0.5834(0.605-1.3574)$ & 0.538 & $0.4462(0.2008-0.9914)$ & 0.044 & $0.7647(0.3785-1.545)$ & 0.469 \\
\hline
\end{tabular}

\section{Discussion}

The existence of a link between human cancers and the MMR determines the relevance of investigations of the DNA mismatch repair system. The inheritance of variations in $M M R$ genes may influence individual susceptibility to the development of colorectal cancer. While the presence of mutation in $h M L H 1$ and $h M S H 2$, leading to MSI-H CRCs is well described, this involves mostly tumors developing in HNPCC. ${ }^{7,16}$ For sporadic CRCs, where MSI-L or MSI stable genotype is observed, it was suggested that impairment in MMR system efficiency may arise from other genes, whose alternations lead to the complete loss of function of heterodimers. ${ }^{17,18}$ That is why hMSH6 was investigated for their possible role in tumor neogenesis in sporadic CRCs. $h M S H 6$ form complex with $h M S H 2$, that recognizes single-base mispairs and small (i.e., single-base) insertion-deletion loops. ${ }^{19}$ Mutations in MSH6 result in a partial loss of mismatch repair. ${ }^{20}$ Human tumor cell lines with MSH6 mutations exhibit MSI primarily in mononucleotide and not in dinucleotide repeats, which suggests its association rather with MSI-L CRCs. Parc, et al. identified 16 hMSH6 alterations. ${ }^{11}$ Fifteen of these were germ-line changes and 1 was a somatic change. Only 2 of the 15 germ-line alterations led to a change in the primary sequence of the hMSH6 protein: Gly39Glu and Leu395Val, both of which are reported to be polymorphisms. ${ }^{10,21}$ By now, few studies investigated the association between the MSH6 Gly39Glu variant and the risk of sporadic colorectal cancer. ${ }^{13,14,21}$ Berndt, et al. reported that homozygosity for the MSH6 39 Glu variant was associated with a more than triple risk of rectal cancer. However, no association was found between the MSH6 variant and colorectal cancer overall. Since the number of rectal cases in this study was small, the authors recommended interpreting the observed association for rectal cancer with caution. ${ }^{13}$ Campbell, et al. analyzed whether MSH6 (Gly39Glu) polymorphisms were associated with the risk of colon cancer in the data from 1,609 colon cancer cases and 1,972 controls. Male participants heterozygous (G/A) or homozygous (A/A) for the MSH6 variant were at $27 \%$ increased risk of colon cancer, while no associations were observed among females. On the other hand, further association was not observed with MSI-negative status of CRCs. Additionally, this study observed effect modification between MMR variants and lifestyle factors that contribute to higher CRC risk overall. $^{14}$

This is the first report concerning polymorphism Gly39 Glu and the risk of colorectal cancer in the Polish population. In our study, GG genotype was more prevalent than the AA genotype. The presence of the MSH6 39Glu variant allele (A) was associated with the increased risk of colon cancer (OR 1.57; 95\% CI: 1.04-2.38; p = 0.032) in the analyzed population. In contrast to the previous study, the homozygosity for A allele did not lead to a higher risk of CRC, but was observed in the cases of heterozygosity (OR 1.65; 95\% CI: 1.01-2.69; p = 0.44). Similar results concerning higher concentration of hMSH6 A allele in CRC cases were obtained in the study by Kolender (23\% in colorectal cancer cases as compared to $15 \%$ in controls), although no formal statistical comparisons were made. ${ }^{21}$ The presence of G/A genotype and A allele were more frequently detected in early stage tumors, which can suggest the possible MSI-H phenotype. Though MSI status was not checked in our study, the linkage between hMSH6 mutation and MSI status is now a matter of wide debate. The lack of a clear association with MSI positive or negative status raises many questions concerning the role of mutations in this gene on the development of MSI-L or MSI-H CRC, or broadly speaking in NHPCC and sporadic colorectal cancers. In comparisons to $h M L H 1$ or $h M L H 2$, the observed mutations in $h M S H 6$ do not cause lesser gene expression in healthy and cancerous tissues. ${ }^{22}$ Plaschke reported that only 3 out of 146 patients with sporadic cancer exhibited abnormal hMSH6 expression, with 2 having germ-line mutations. However, possible missense mutations may be present that impair gene function without substantially affecting protein expression or resulting in the MSI-H phenotype. ${ }^{15} \mathrm{Wu}$ et al. emphasized that an MSI-low phenotype cannot be considered an exclusion criterion for mutation testing of $M M R$ 
genes in general. ${ }^{12}$ Still, we can suspect that a fair amount of sporadic cancers can arise in HNPCC-like families, in which, though not evident, the MSI-H phenotype and other MMR genes mutations may be present. The possible answers may also involve epigenetic or somatic changes whose impact on carcinogenesis is intensified by the presence of environmental factors such as smoking or a Western diet. This idea of investigating the interactions between environmental exposures and MMR polymorphisms is strengthened by findings of increased oxidative stress and DNA damage resulting from tobacco smoking as well as from a Western diet, alcohol and obesity. ${ }^{23-26}$ However, for a better explanation of these phenomena further research is warranted.

\section{References:}

1. Center MM, Jemal A, Ward E. International trends in colorectal cancer incidence rates. Cancer Epidemiol Biomarkers Prev. 2009;18(6):1688-1694.

2. American Cancer Society. Colorectal Cancer Facts \& Figures 20142016. Color Cancer Facts Fig. 2014;1-32.

3. Samadder NJ, Vierkant RA, Tillmans LS, et al. Associations between colorectal cancer molecular markers and pathways with clinicopathologic features in older women. Gastroenterology. 2013;145(2):348-356.

4. Ionov Y, Peinado MA, Malkhosyan S, Shibata D, Perucho M. Ubiquitous somatic mutations in simple repeated sequences reveal a new mechanism for colonic carcinogenesis. Nature. 1993;363(6429):558-561.

5. Pritchard CC, Grady WM. Colorectal cancer molecular biology moves into clinical practice. Gut. 2011;60(1):116-129.

6. Lichtenstein P, Holm NV, Verkasalo PK, et al. Environmental and heritable factors in the causation of cancer: Analyses of cohorts of twins from Sweden, Denmark, and Finland. $N$ Engl J Med. 2000;343(2):78-85.

7. Aaltonen L, Johns L, Jarvinen H, Mecklin JP, Houlston R. Explaining the familial colorectal cancer risk associated with mismatch repair (MMR)-deficient and MMR-stable tumors. Clin Cancer Res. 2007;13(1):356-361.

8. Theodoratou E, Montazeri Z, Hawken S, et al. Systematic meta-analyses and field synopsis of genetic association studies in colorectal cancer. J Natl Cancer Inst. 2012;104(19):1433-1457.

9. Valle L. Genetic predisposition to colorectal cancer: Where we stand and future perspectives. World J Gastroenterol. 2014;20(29): 9828-9849.

10. Nicolaides NC, Palombo F, Kinzler KW, Vogelstein B, Jiricny J. Molecular cloning of the N-terminus of GTBP. Genomics. 1996;31(3):395-397.

11. Parc $Y R$, Halling $K C$, Wang $L$, et al. HMSH6 alterations in patients with microsatellite instability-low colorectal cancer. Cancer Res. 2000;60(8):2225-2231.

12. Wu Y, Berends MJ, Mensink RG, et al. Association of hereditary nonpolyposis colorectal cancer-related tumors displaying low microsatellite instability with MSH6 germline mutations. Am J Hum Genet. 1999;65(5):1291-1298.

13. Berndt SI, Platz EA, Fallin MD, Thuita LW, Hoffman SC, Helzlsouer KJ. Mismatch repair polymorphisms and the risk of colorectal cancer. Int J Cancer. 2007;120(7):1548-1554.

14. Campbell PT, Curtin K, Ulrich CM, et al. Mismatch repair polymorphisms and risk of colon cancer, tumour microsatellite instability and interactions with lifestyle factors. Gut. 2009;58(5):661-667.

15. Plaschke J, Krüger S, Pistorius S, Theissig F, Saeger HD, Schackert HK. Involvement of hMSH6 in the development of hereditary and sporadic colorectal cancer revealed by immunostaining is based on germline mutations, but rarely on somatic inactivation. Int J Cancer. 2002;97(5):643-648.

16. Cunningham JM, Kim CY, Christensen ER, et al. The frequency of hereditary defective mismatch repair in a prospective series of unselected colorectal carcinomas. Am J Hum Genet. 2001;69(4):780-790.
17. Percesepe A, Kristo $P$, Aaltonen LA, Ponz de Leon $M$, de la Chapelle A, Peltomaki P. Mismatch repair genes and mononucleotide tracts as mutation targets in colorectal tumors with different degrees of microsatellite instability. Oncogene. 1998;17(2):157-163.

18. Jass JR, lino $H$, Ruszkiewicz $A$, et al. Neoplastic progression occurs through mutator pathways in hyperplastic polyposis of the colorectum. Gut. 2000;47(1):43-49.

19. Johnson RE, Kovvali GK, Prakash L, Prakash S. Requirement of the yeast MSH3 and MSH6 genes for MSH2-dependent genomic stability. J Biol Chem. 1996;271(13):7285-7288.

20. Papadopoulos N, Nicolaides NC, Liu B, et al. Mutations of GTBP in genetically unstable cells. Science. 1995;268(5219):1915-1917.

21. Kolodner RD, Tytell JD, Schmeits JL, et al. Germ-line MSH6 mutations in colorectal cancer families. Cancer Res. 1999;59:5068-5074.

22. Cawkwell L, Gray S, Murgatroyd H, et al. Choice of management strategy for colorectal cancer based on a diagnostic immunohistochemical test for defective mismatch repair. Gut. 1999;45(3):409-415.

23. Phillips DH. Smoking-related DNA and protein adducts in human tissues. Carcinogenesis. 2002;23(12):1979-2004.

24. Jagerstad M, Skog K. Genotoxicity of heat-processed foods. Mutat Res. 2005;574(1-2):156-172.

25. Wu D, Zhai Q, Shi X. Alcohol-induced oxidative stress and cell responses. J Gastroenterol Hepatol. 2006;21(Suppl 3):26-29.

26. Vincent $H K$, Innes $K E$, Vincent KR. Oxidative stress and potential interventions to reduce oxidative stress in overweight and obesity. Diabetes Obes Metab. 2007;9(6):813-839. 